\title{
Algal bloom prevention based on the hydrological process regulation in the middle and lower Han River
}

\author{
Jian $\mathrm{Li}^{1}$, Wei Yin ${ }^{1}$, Haiyan $\mathrm{Jia}^{1}$, and Xiaokang Xin ${ }^{1}$ \\ ${ }^{1}$ Changjiang Water Resources Commission
}

May 6, 2020

\begin{abstract}
Han River, the largest tributary of the Yangtze River in China, has experienced at least 10 large-scale algal blooms since 1992 because of eutrophication and hydrological/hydraulic regime alteration. Eutrophication control is a long-term process, but the regulation of hydrological process is a direct and effective way to prevent algal blooms. In this study, we attempted to find the difference of hydrological process between the years with and without algal blooms. Hydrological statistics and numerical simulation results show that the key high-flow processes were missing in early spring when algal blooms occur. The hydrological processes in the middle and lower Han River have undergone major changes because of the impoundment of the middle route of the South-to-North Water Diversion Project. The construction of cascade reservoirs in the middle and lower Han River, such as in Xinglong, have weakened the hydrodynamic conditions in the damming river sections, thereby providing favourable hydrological conditions for the occurrence of algal blooms. During the critical period for algal growth from January to March, the cross-sectional average velocity and discharge in the years with algal blooms were significantly lower than those years without algal blooms. The threshold levels of flow rate for algal bloom prevention at the Shayang to Xiantao River section were $1100 \mathrm{~m} 3 \mathrm{~s}-1$ ( $0.24 \mathrm{~m} \mathrm{~s}-1)$ and $810 \mathrm{~m} 3 \mathrm{~s}-1$ (0.74 m s-1), respectively. We developed the hydrological process regulation schemes on the basis of the hydrological/hydraulic thresholds according to the different sections where algal blooms occur from two aspects: a) single reservoir operations, such as full-emptying and water level fluctuation operations; and b) joint operation of cascade reservoirs and the Water Diversion Project from Yangtze to Han River.
\end{abstract}

\section{Hosted file}

Jian Li-Algal bloom prevention based on the hydrological process regulation in the middle and lower Han available at https://authorea.com/users/317807/articles/447908-algal-bloom-prevention-basedon-the-hydrological-process-regulation-in-the-middle-and-lower-han-river

\section{Hosted file}

TABLE1-Statistics on the historical algal blooms in the middle and lower Han River.doc available at https://authorea.com/users/317807/articles/447908-algal-bloom-prevention-basedon-the-hydrological-process-regulation-in-the-middle-and-lower-han-river

\section{Hosted file}

TABLE 2-Statistics of flow velocity and the daily mean water discharge from January to March in the yea available at https://authorea.com/users/317807/articles/447908-algal-bloom-prevention-basedon-the-hydrological-process-regulation-in-the-middle-and-lower-han-river

\section{Hosted file}

TABLE 3-Response of the average velocity of the Shayang section to the water level fluctuation in front available at https://authorea.com/users/317807/articles/447908-algal-bloom-prevention-based- 
on-the-hydrological-process-regulation-in-the-middle-and-lower-han-river

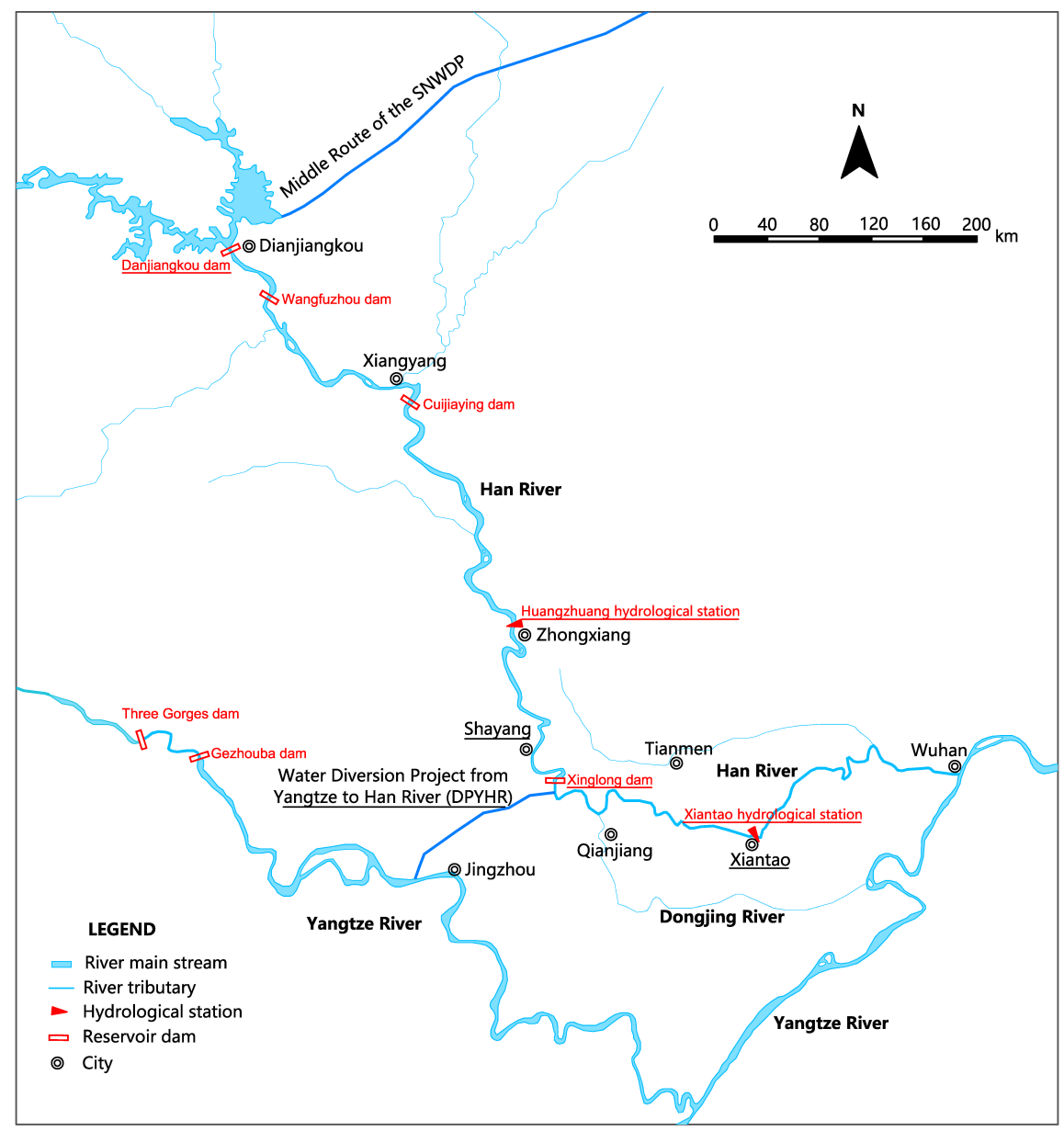



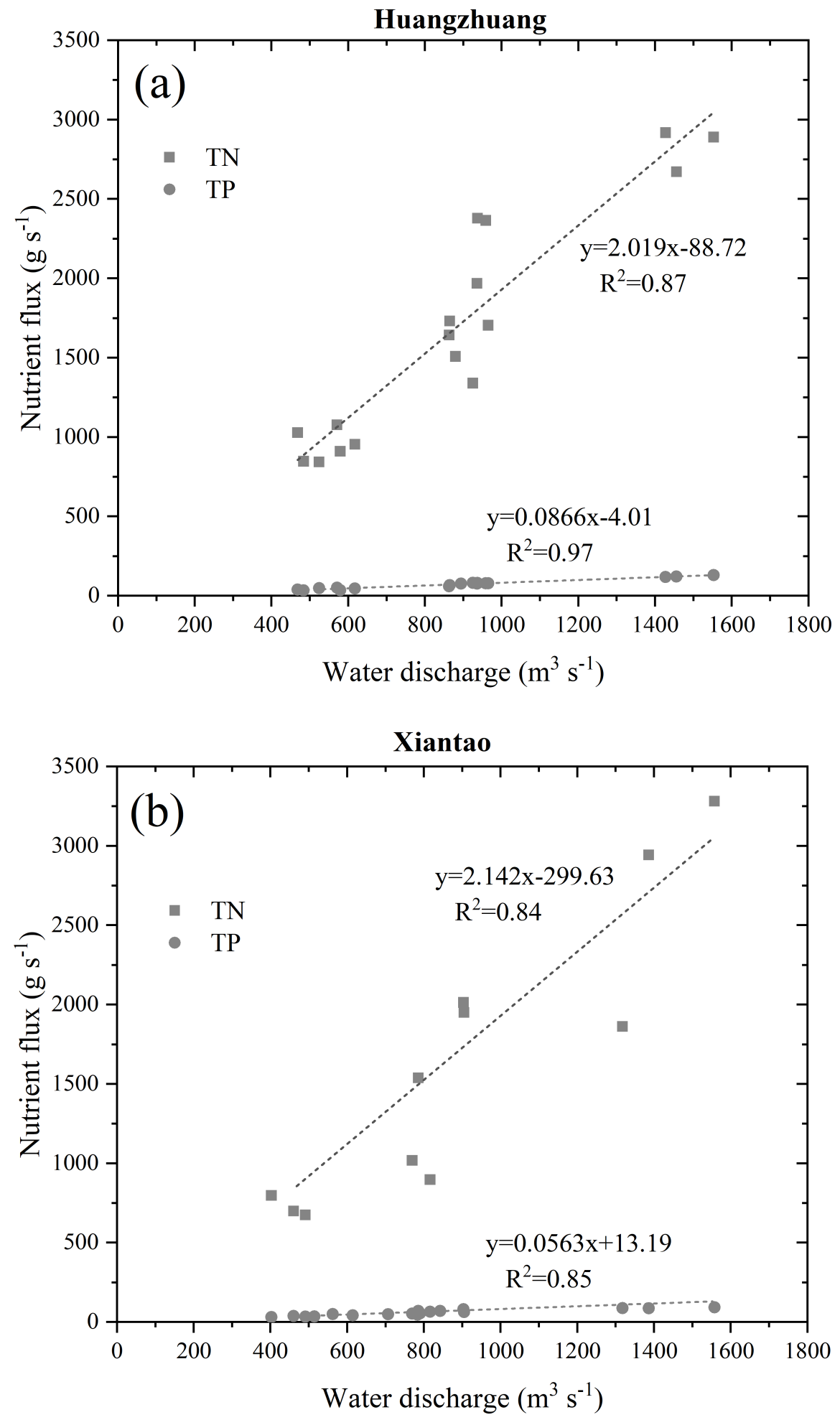


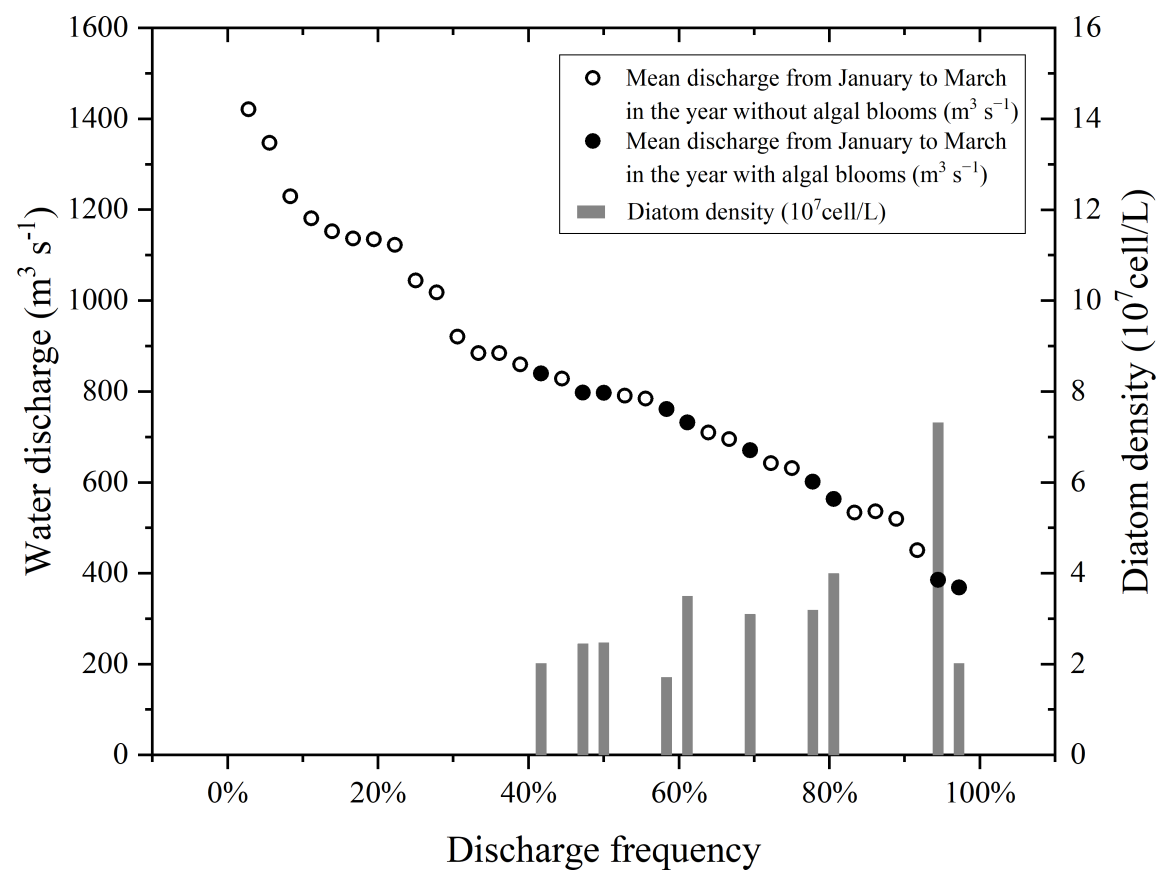




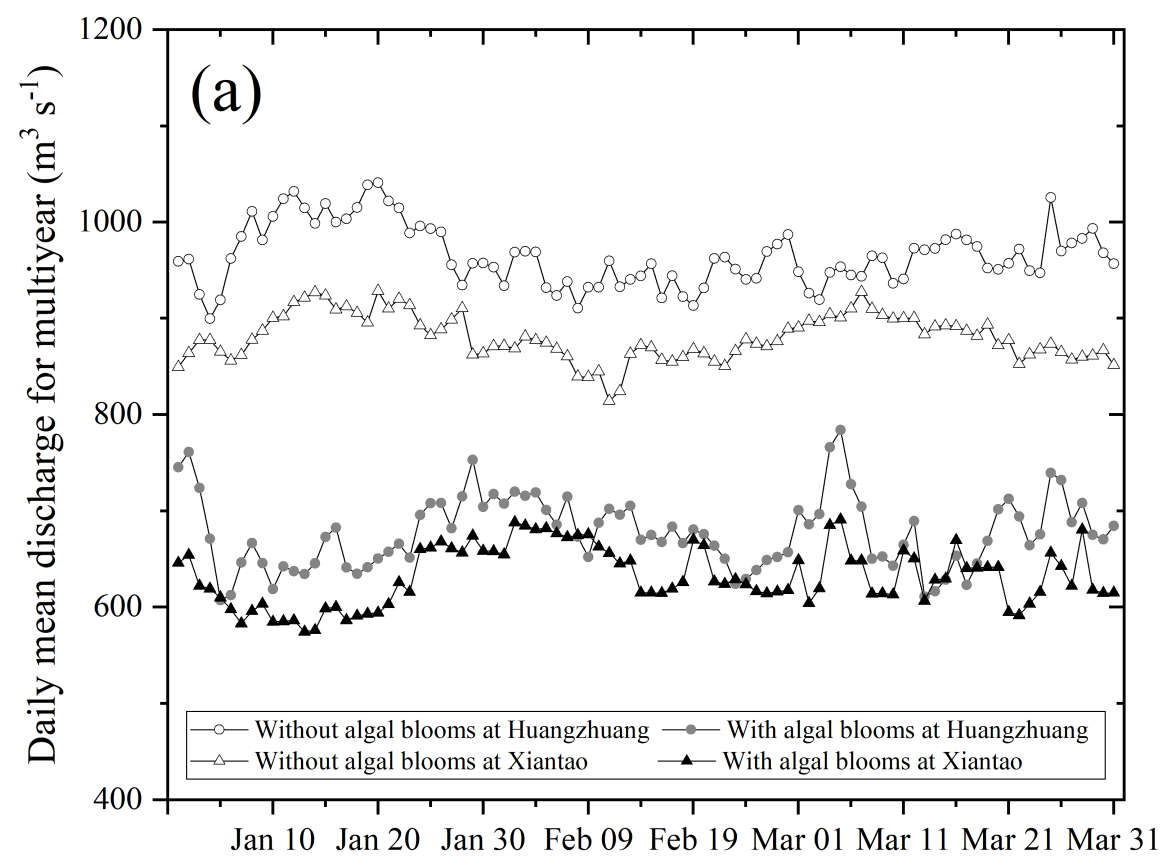

Date

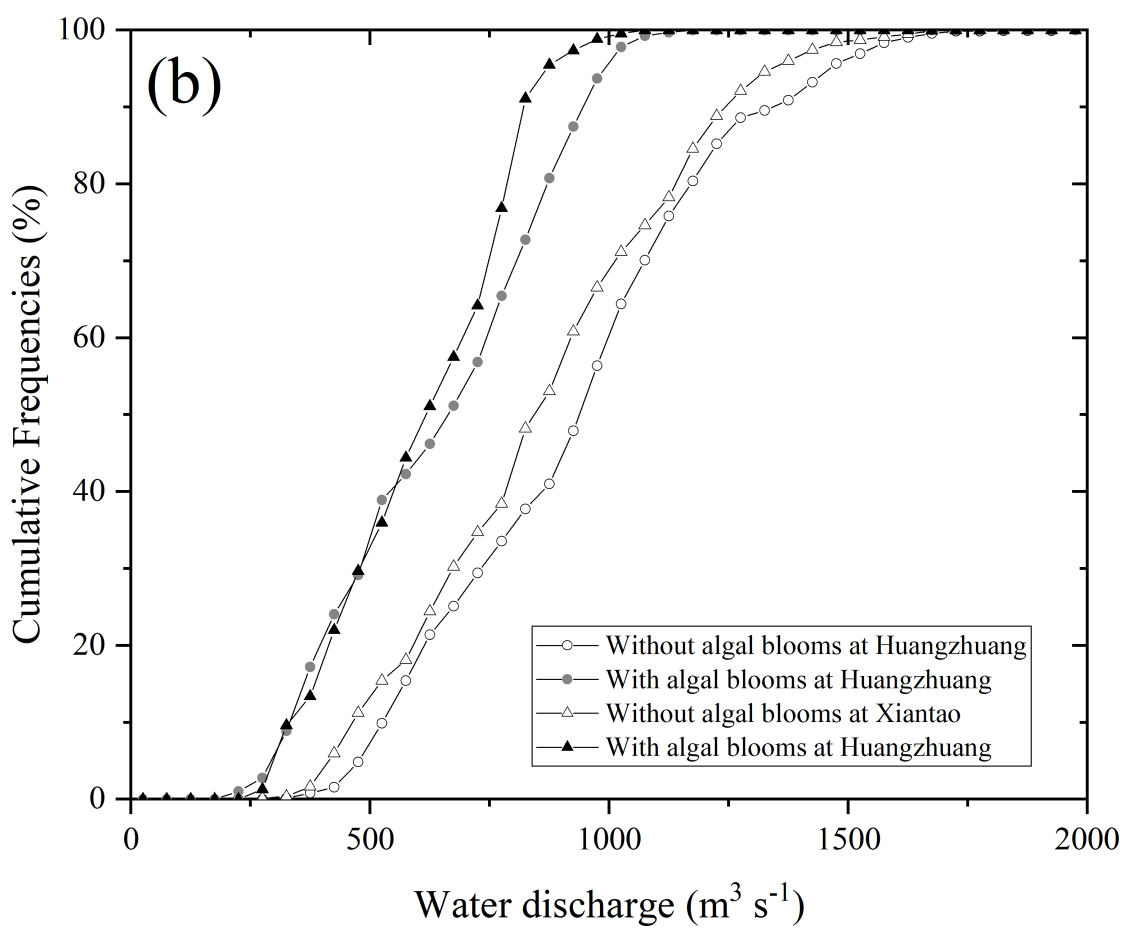




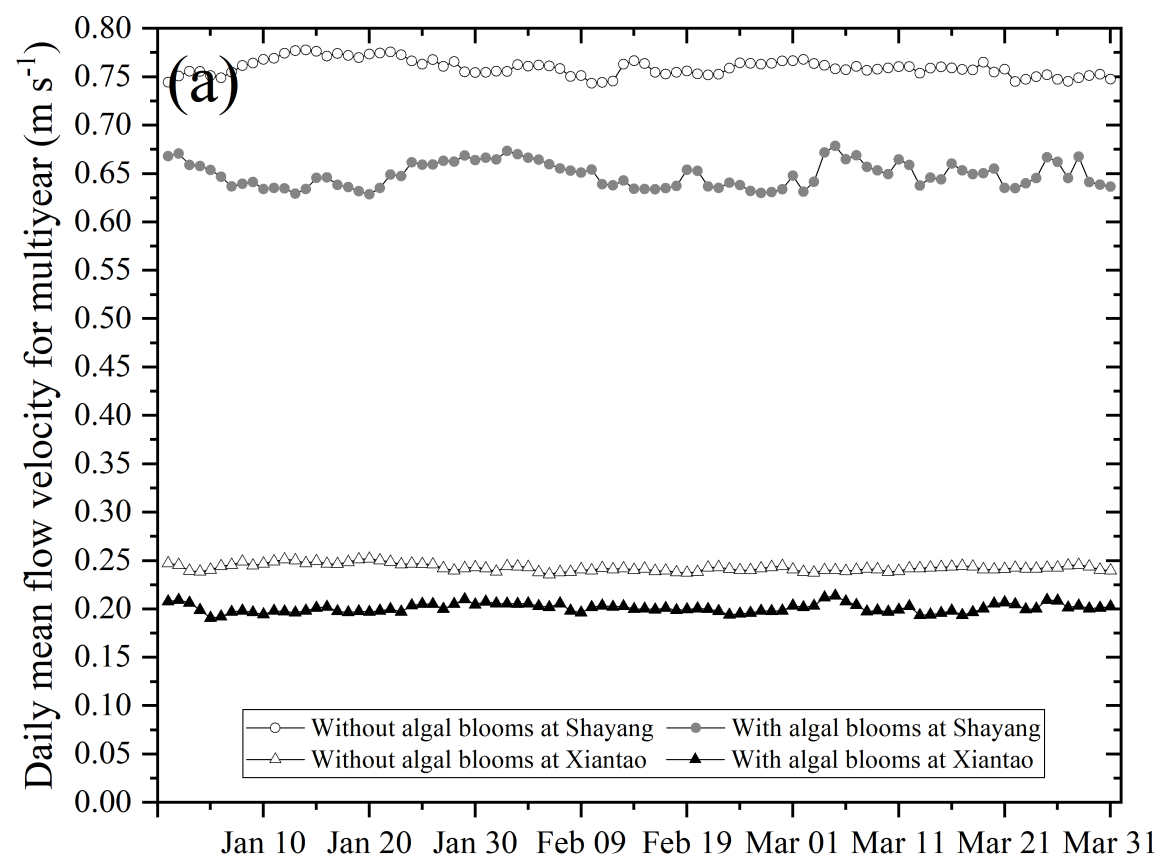

Date

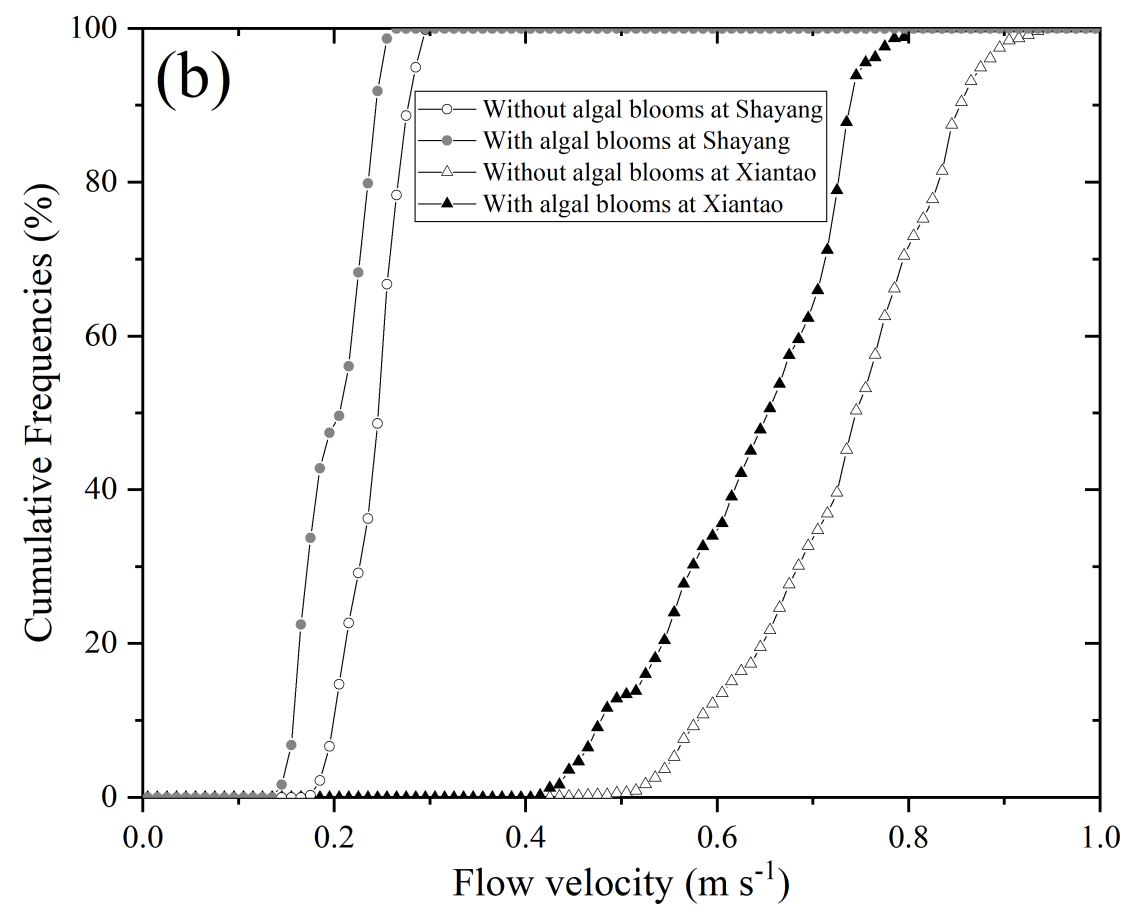




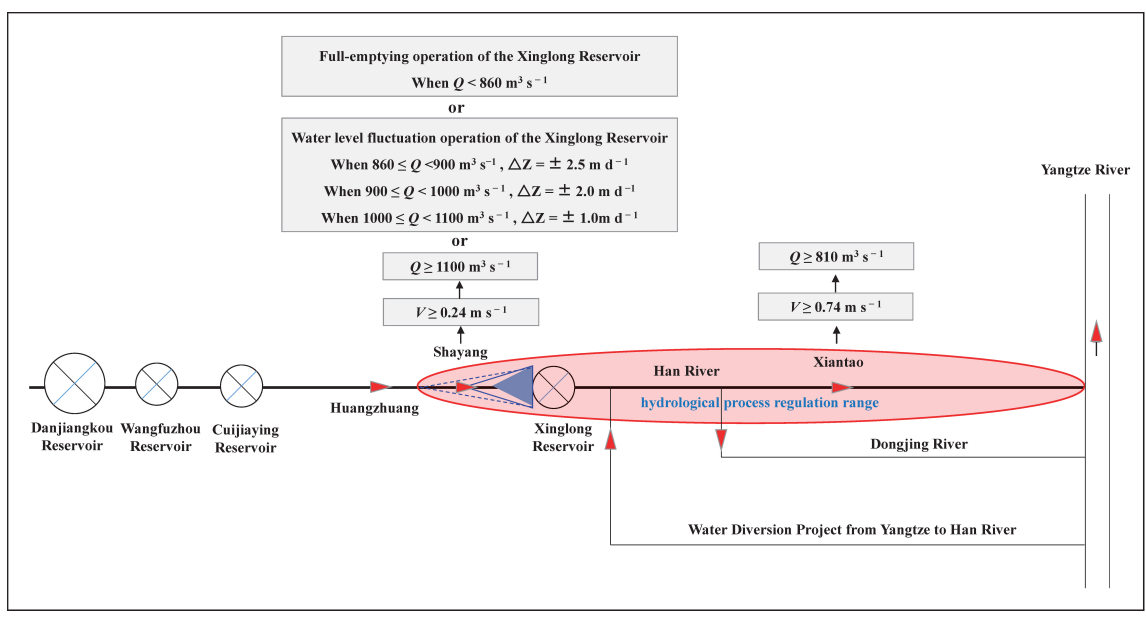



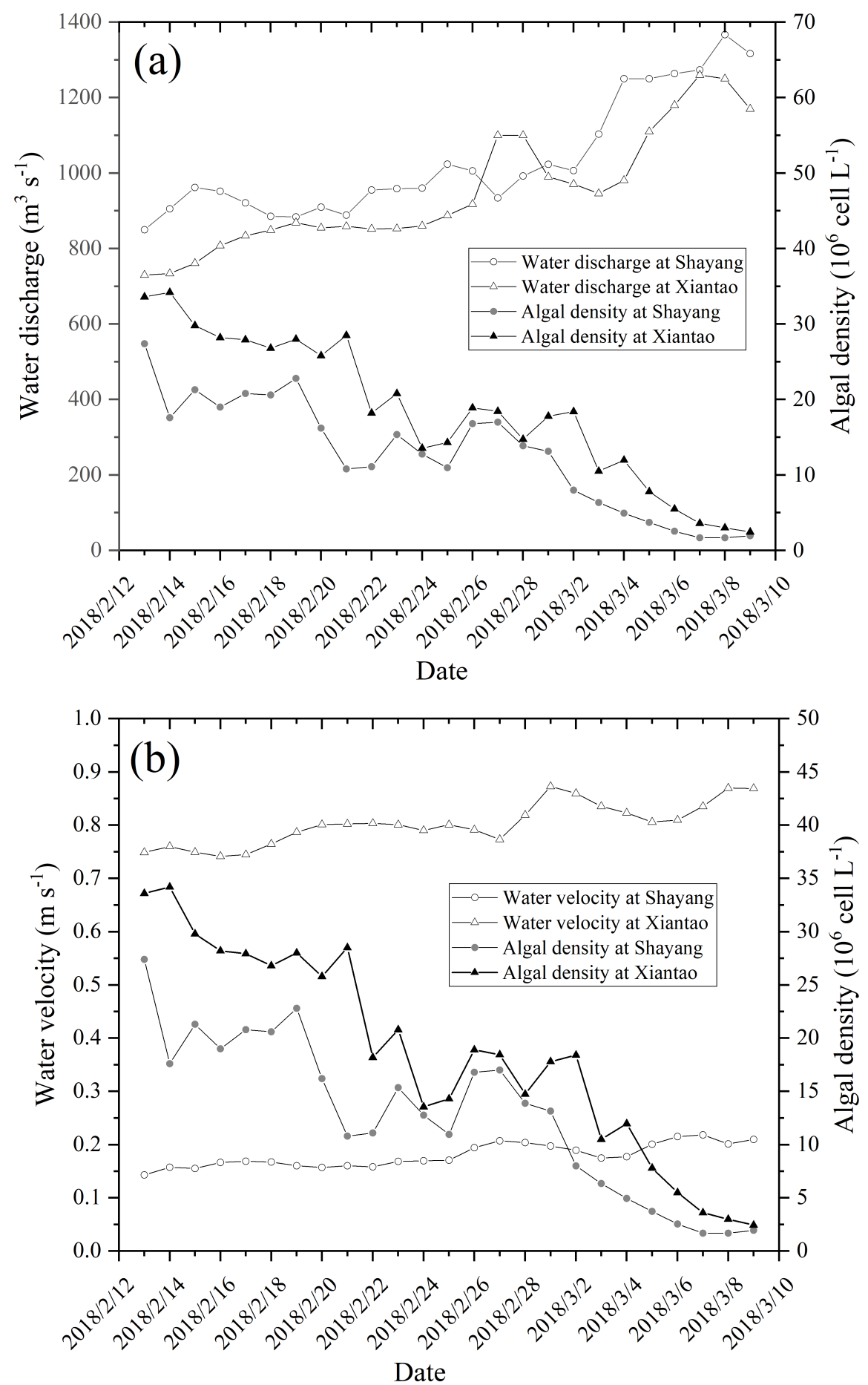